\title{
Differences in presentation of symptoms between women and men with intermittent claudication
}

\author{
Birgitta Sigvant ${ }^{1,2^{*}}$, Fredrik Lundin ${ }^{3}$, Bo Nilsson ${ }^{4}$, David Bergqvist ${ }^{5}$ and Eric Wahlberg ${ }^{1,6}$
}

\begin{abstract}
Background: More women than men have PAD with exception for the stage intermittent claudication (IC). The purpose of this study was to evaluate differences in disease characteristics between men and women when using current diagnostic criteria for making the diagnosis $\mid C$, defined as $A B \mid<0.9$ and walking problems.
\end{abstract}

Study Design: Cohort study

Methods: 5040 elderly (median age 71) subjects participated in a point-prevalence study 2004. They had their ABI measured and filled out questionnaires covering medical history, current medication, PAD symptoms and walking ability. The prevalence of IC was $6.5 \%$ for women and $7.2 \%$ for men $(P=0.09)$. A subset of subjects with IC $(N=$ 56) was followed up four years later with the same procedures. They also performed additional tests aiming to determine all factors influencing walking ability.

Results: Men with IC had more concomitant cardiovascular disease and a more profound smoking history than women. Women, on the other hand, reported a lower walking speed $(P<0.01)$ and more joint problems $(P=$ 0.018). In the follow up cohort $\mathrm{ABl}$, walking ability and amount of atherosclerosis were similar among the sexes, but women more often reported atypical IC symptoms.

Conclusion: Sex differences in the description of IC symptoms may influence diagnosis even if objective features of PAD are similar. This may influence accuracy of prevalence estimates and selection to treatment.

\section{Background}

Peripheral arterial disease (PAD) is common in western countries, affecting almost $20 \%$ of elderly populations and its prevalence differs between sexes. Findings of the Swedish PAD Prevalence Study (SPPS) revealed that women are more likely to suffer from PAD when diagnosis is based only on ankle brachial indices (ABI) but when diagnosis relies on additional assessment of symptoms (ie IC) sex differences disappears [1,2].

The prevalence of IC is around 7\% among elderly [1], and considerably diminishes patients' quality of life (QoL) $[3,4]$ The extent of this influence on QoL determines whether surgical intervention is indicated. Accordingly, a correct diagnosis, accurate assessment of disease severity and weighing the risk associated with

\footnotetext{
* Correspondence: birgitta.sigvant@liv.se

${ }^{1}$ Karolinska Institutet, Stockholm, Sweden

Full list of author information is available at the end of the article
}

the procedure against the magnitude of potential symptomatic improvement is essential for recommending the best treatment option. A correct diagnosis is also essential to enable appropriate modification of cardiovascular $(\mathrm{CV})$ risk factors and to prevent $\mathrm{CV}$ morbidity and death [5].

There are some reports in the literature that men and women with IC are treated differently [6,7]. One example is the amount of resources spent on treatment. According to the Swedish Vascular Registry men undergo more interventions for IC than women [8]. Another example is that women appear to seek treatment when they have more advanced disease than men [6]. It is possible that a sex difference in prevalence is the explanation for this, but patients' perception of their symptoms may also contribute to these observations. The latter is further supported by comparable data for ischemic heart disease $[9,10]$. Accordingly, any occurring 
sex difference in IC disease characteristics that may influence making the diagnosis needs to be clarified, since it may influence epidemiologic data and selection to treatment.

We hypothesized that there might be differences in perception of IC symptoms, risk factor occurrence and extent of leg artery atherosclerosis between men and women that may influence diagnosis. The purpose of this study was to evaluate differences in disease characteristics between men and women when using current diagnostic criteria for making the diagnosis IC.

\section{Methods}

The study consists of two parts: A) an analysis of sex differences in risk factors among IC patients in a large cohort of Swedish elderly habitants, and B) an in-depth analysis of IC disease characteristics in a smaller sample from this cohort.

The main purpose of Part A cohort was to estimate general sex differences in perception of walking ability in elderly with and without IC using the SPPS. Briefly, this population based point-prevalence study was conducted in four Swedish regions during 2004 and included questionnaire results of 5080 men and women taken from 8000 randomly selected participants aged 60-90 years. They also had their ABI measured. In this cohort 6.8\% (CI 6.5-7.1) had IC. [1]. Questionnaire data collected included details in walking ability, self reported concomitant diseases, medication use, and risk factor occurrence. A detailed description of study design, methodology and validity of SPPS has been published previously [7]. For Part B all subjects with IC living in one of the region (Karlstad) were invited to a follow up study. The purpose of Part B was to elucidate any sex differences in leg artery atherosclerosis distribution, walking ability, perception of symptoms, as well as detecting if any severe heart failure was contributing to a possibly observed sex difference in walking ability

\section{Study populations}

Part A uses the following cohorts from SPPS:

Group 1. IC; All subjects with ABI $<0.9$ and a positive answer in Rose questionnaire [11], $(\mathrm{N}=333$, 180 women and 153 men).

Group 2. Control group; All subjects with ABI > 0.9 and a negative answer in Rose questionnaire $(\mathrm{N}=$ 3313, 1734 women and 1579 men).

A subgroup from Group 1 was used for Part B:

Group 3. Subgroup IC; All subjects from Group 1 living in one of the regions used 2004 (Karlstad, N = 88, 51 women and 37 men) screened for possible enrolment in the follow-up study. Nineteen had died in 2008 (nine of CV causes, five defined as non-CV and for five subjects data was missing) the remaining 69 subjects were invited. Of those $81 \%(\mathrm{n}=56)$ of the survivors, 35 women agreed to participate. Ten of those subjects were assessed to a home visit because of immobility and only answered the questionnaires and had ABI measured.

\section{Analyses \\ Part A}

Walking Impairment Questionnaire (WIQ) answers, ABI values, Rose questionnaire answers, smoking habits, medication use and concomitant diseases were analyzed for Groups 1 and 2 using data collected 2004.

Concomitant diseases, medication and smoking use were self-reported by the subjects. More details about its use and analysis in presented in a previous publication from SPPS [1].

WIQ is divided in three components estimating walking distance, walking speed and stair-climbing ability [12]. For each component subjects rank the degree of difficulties on a scale from 0 to $4(0=$ unable, $4=$ no difficulties) and a summary score is then calculated for each component as a percentage $(\%$ score $=$ individual score $/ 4 \times 100)$.

ABI was defined as the ratio of the lowest systolic pressure of the two measured arteries in the ankle divided by systolic blood pressure in the arm [13].

\section{Part B}

Collected background data consisted of the following

- Medical history (risk factors, co-morbidities and medication use as in Part A),

- Death rate and cause of death (obtained from hospital records),

- ABI (as in Group A).

Part B also covered additional tests to further assess walking ability and QoL:

- Six-minutes walking test (6MWT) [14], which assesses peak walking distance. It took place indoors in a $50 \mathrm{~m}$ long hallway with marks every $5 \mathrm{~m}$. Subjects were asked to cover as many laps as possible in 6 minutes. If the subject needed to stop for any reason he or she was allowed to rest but encouraged to resume walking. The clock continued to run during the resting period. The time to the first stop, the cause of the stop and the total distance were recorded.

- Intermittent Claudication Questionnaire (ICQ) is a disease specific instrument for evaluation of QoL. 
It consists of 16 questions, four evaluating walking distance and stair climbing ability. The results obtained from these questions are presented in a six-graded scale (from totally limited to no limitation at all). The remaining 12 questions correlate with the questionnaires EuroQoL and SF-36 and evaluate daily routines, including physical activities, social activities and physical health, and is scored in a five graded scale [15]. Subjects' responses to each question are summed up and transformed to a 0 to 100 scale, where 0 (the opposite of the WIQ system) is best possible and 100 the worst possible health state.

Examinations in this group also aimed to describe atherosclerotic disease distribution and evaluate effects of heart disease on walking ability:

- Duplex ultrasound (DUS) scanning of leg arteries covered the arterial segments from aortic bifurcation to the Popliteal artery below the knee.

- Echocardiography was performed and as an index of left ventricular systolic function, ejection fraction (EF) was calculated using the apical biplane Simpson's method of discs [16].

Details of these methods and their evaluation is provided at the end of this manuscript as an appendix (Additional file 1).

A left ventricular ejection fraction (EF) less than 50\% was considered as an index of impaired systolic function.

Part B also included a descriptive analysis of symptoms using a semi-structured interview. It was conducted by asking each subject eight questions with open answering alternatives (Table 1). Questions were designed together with an expert nurse in QoL research. The interview took place in a quiet consulting room and a tape recorder was used.

\section{Ethical approval}

The sub-study was approved by the Ethics committee at Uppsala University (Dnr 2008/056). and SPPS by five separate committees Stockholm (KI 03-538), Umeå

\section{Table 1 Semi-structured Interview Questions}

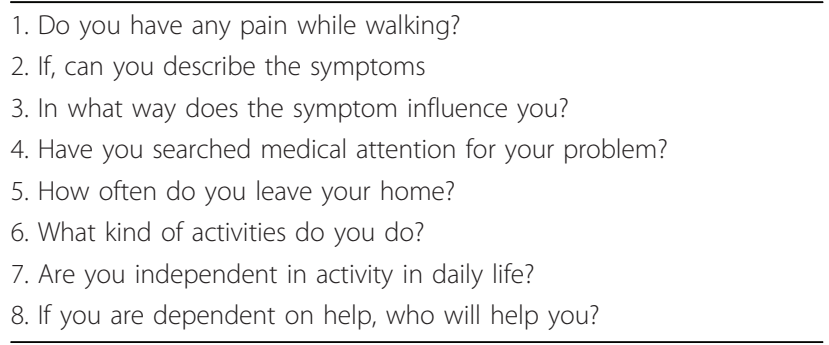

University (Dnr 03-459) Lunds University (Dnr832-0) Uppsala University (Dnr 03-564) and Örebro (Dnr 37403). Informed consent was obtained from each participant.

\section{Statistics}

Binary data was described using numbers and proportions. For age we used sample means and standard deviations. All other data are described by medians and interquartile range (IQR). For ABI we used non-parametric statistics (both descriptive and adjusted by means of non-parametric quartile regression on the median) since it showed significant deviations (Shapiro-Wilks test, $\mathrm{p}<0.001$ ) from the normal distribution. Within group differences between sexes was compared using Mann-Whitney U-test. Presented correlations are Spearman rank correlations tested for deviations from the null hypothesis using an asymptotic test. For comparing proportions between sexes we used Fisher's exact test. All analyses were performed with STATA/IC for Windows version 10 (STATA Corp LP. College Station, Texas). P-values below level 0.05 were considered to be statistically significant.

\section{Results}

\section{Part A}

Baseline data for Group 1(IC patients) $(\mathrm{n}=333)$ and Group 2 (control subjects) $(\mathrm{n}=3322)$ are presented in Table 2. Group 1 subjects were older compared to Group 2 ( $\mathrm{p}<0.001)$. Men were more likely to have suffered a stroke in both groups (Group $1 \mathrm{p}<0.001$; Group $2 \mathrm{p}=0.007)$. In Group 1 men were more likely to suffer from DM than women $(p=0.047)$, and in both groups men were more likely to have CAD than women (Group 1 men $\mathrm{p}<0.001$; Group $2 \mathrm{p}<0.001$ ). Smoking habits, while more common in Group 1 compared to Group $2(62.5 \%$ vs $50.8 \%, \mathrm{p}<0.001)$, revealed similar patterns from a sex perspective in both groups. There was however an increased likelihood of a smoking history in men (Group $1 \mathrm{p}<0.001$; Group $2 \mathrm{p}<$ 0.001 ).

Walking distance $(\mathrm{p}<0.001)$ and speed $(\mathrm{p}<0.001)$ as well as stair climbing ability $(\mathrm{p}<0.001)$ were significantly worse for women as compared to men in Group 1. While women in Group 2, experienced more problems with lower walking speed $(\mathrm{p}=0.013)$, joint problems $(\mathrm{p}=0.018)$ and heart palpitations $(\mathrm{p}=0.002)$.

\section{Part B}

Women and men in Group 3 decreased ABI values between 2004 and 2008 to a similar extent, from 0.67 (SD 0.13) to $0.44(0.39)$ in men and $0.69(0.15)$ to 0.44 $(0.40)$ in women $(\mathrm{p}>0.001)$. Walking ability as assessed by WIQ also changed during the four years in all 


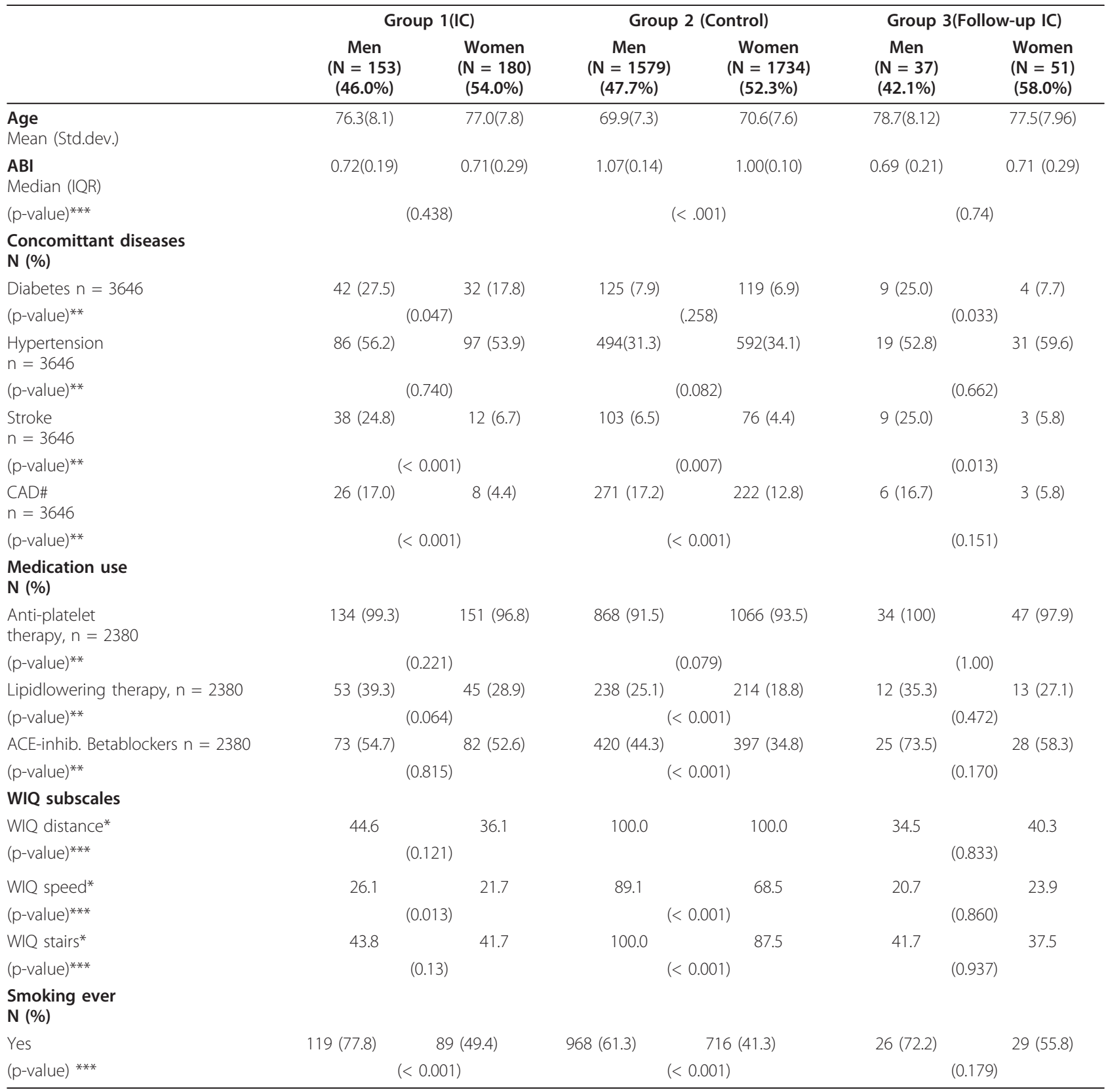

domains for men who reported declined scores for pain 78.6(SD 19.8) to 66.2 (30.6), distance from 54.2 (36.4) to 35.4 (30.6) and for speed from 34.9 (22.9) to 20.1 (20.2). The corresponding figures for women were for pain, distance- and speed respectively; 65.7 (33.8) to 76.4 (33.2), 47.3 (35.8) to 49.3 (41.7) and 31.5 (25.8) to 21.8 (14.6).

Walking distances were similar between the sexes, with pain free distance of $111 \mathrm{~m}$ (SD 132) for men and $137 \mathrm{~m}$ (SD 160) for women ( $\mathrm{P}=0.58)$, and absolute distances of $288 \mathrm{~m}$ (SD 138) for men and $296 \mathrm{~m}$ (SD 160) for women $(\mathrm{P}=0.19)$.
ICQ data showed that women spent more time thinking about leg pain $(p=0.045)$ and although not statistically significant showed that men were more likely to report severe leg pain, $(p=0.067)$ (Table 3). There was no significant difference in the presence of vessel stenosis identified on DUS between men and women at the level of the Iliac artery $(p=0.373)$, Superficial Femoral artery $(\mathrm{p}=0.513)$, and or Politeal artery $(\mathrm{p}=1.0)$ (Figure 1). For the heart. left ventricular systolic dysfunction tended to be more common in men, with a reduced ejection fraction in $41 \%$ of men compared to $15 \%$ of 
Table 3 Responses of the Intermittent Claudication Questoinnaire in Group 3 (Subgroup IC)

\begin{tabular}{|c|c|c|c|c|c|c|c|}
\hline \multirow[t]{2}{*}{ Score Median and Quartiles (Q) } & \multicolumn{3}{|c|}{ Men } & \multicolumn{3}{|c|}{ Women } & \multirow[t]{2}{*}{ P-value* } \\
\hline & Q1 & Median & & Q1 & Median & Q3 & \\
\hline Severity of leg pain & 3 & 3 & 4 & 0.75 & 3 & 4 & 0.067 \\
\hline Pain limiting using bus, train or tube & 0 & 0 & 2 & 0 & 0 & 2 & 0.992 \\
\hline Pain limiting climbing several flights of stairs & 0 & 0 & 0 & 0 & 1 & 2 & 0.346 \\
\hline Pain limiting climbing one flight of stairs & 2 & 3 & 3 & 1 & 2 & 4 & 0.319 \\
\hline Pain limiting walking more than 1 mile & 1 & 1 & 2 & 0 & 1 & 3 & 0.551 \\
\hline Pain limiting walking 100 yards & 2.5 & 3 & 4 & 1 & 4 & 4 & 0.934 \\
\hline Pain limiting leaving house & 0 & 1 & 2 & 0 & 0 & 2 & 0.827 \\
\hline Pain when stopped walking & 0 & 1 & 3 & 0 & 1 & 3 & 0.972 \\
\hline Time spent thinking about leg pain & 0 & 1 & 3 & 0 & 2 & 3 & 0.045 \\
\hline Felt downhearted and low because of pain & 2 & 3 & 3 & 1 & 2 & 3 & 0.075 \\
\hline Time spent worrying that pain will worsen & 0 & 1 & 2.5 & 0 & 1 & 3 & 0.640 \\
\hline Interference with normal work & 1 & 2 & 2.5 & 0 & 1 & 2 & 0.162 \\
\hline
\end{tabular}

$(0=$ best possible health state, $4=$ worst possible health state)

* P-values comparing differences between sexes using Mann-Whitney's U-test.

women $(P=0.06)$. No significant correlation was observed between EF and 6MWT distances $($ rho $=0.21$, $\mathrm{p}=0.19)$.

Men presented classic IC symptoms (i.e. pain and cramp) in the interview (Table 1 question 2) more frequently than women who in turn more often described symptoms as tiredness, unsteadiness, numbness and sorrow $(75 \%$ vs. $41 \% \mathrm{p}=0.086)$. A higher proportion of men regularly left their homes $(25 \% \mathrm{vs} 7 \%, \mathrm{p}=0.097)$, and men sought medical care three times as often as women $(67 \%$ vs $19 \% \mathrm{p}=0.011)$. Sixty-three percent of the interviewed men (and 52\% of women) were

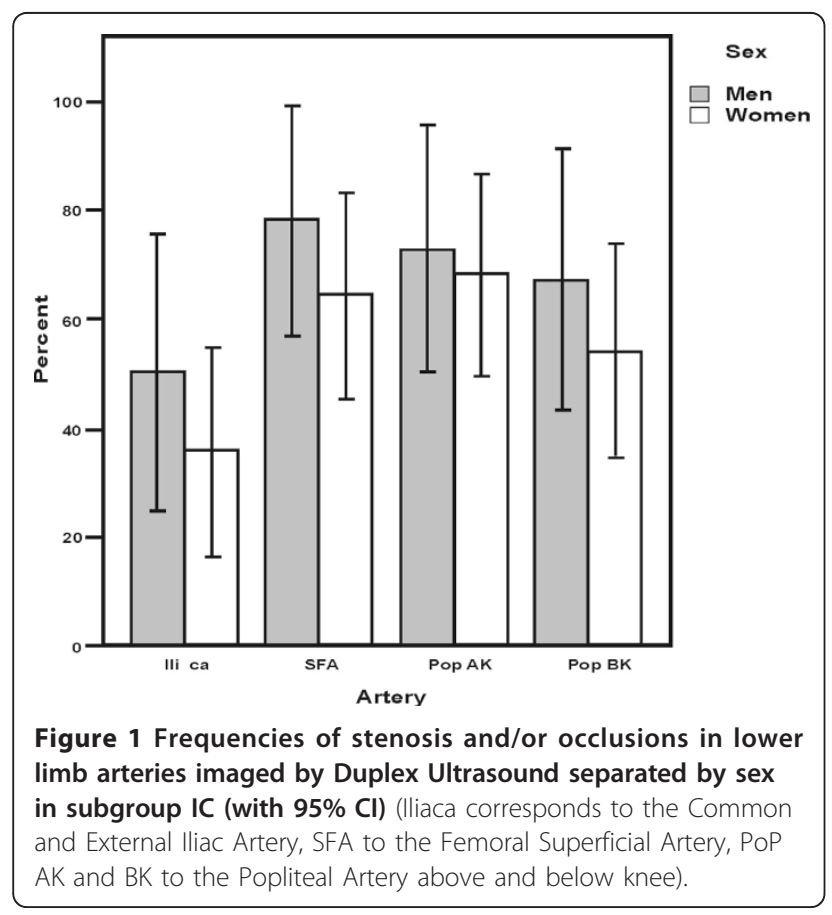

dependent on aid and a majority of them was supported by their spouses $(89 \%)$, whereas women used professional assistance $(57 \%)$ or their children (36\%).

\section{Discussion}

This study presents some new findings that may be of importance when diagnosing and evaluating IC. First, men are more likely to have suffered from a CV disease than women and women tend to perceive a reduced walking ability more often than men do regardless if they are diagnosed as suffering from IC or not. Second, women and men diagnosed with IC appear to have similar extent and type of disease when objective measures are employed. Third, when these IC patients are interviewed about their problems, women more often describe a reduced need of walking ability, or habit of walking compared to men.

Men have a greater CV disease burden than women in the present study, which is a common finding throughout the current published literature. It is valid also after adjustment for age $[17,18]$ and supports the notion that IC should be more common in men [2,19-21]. IC was indeed more common in men in the few early IC prevalence studies that enrolled women $[20,22]$, but more recent publications report a sex neutral prevalence [23-25]. The reasons for a diverging pattern in prevalence for IC compared to other PAD stages could be explained by most epidemiological studies use of only questionnaire as diagnostic tool for IC diagnosis [26]. In Part A of this study that combined questionnaires with ABI for IC diagnosis it appears that the IC patients are correctly diagnosed. This is supported by Duplex findings of leg artery in the follow up study. Accordingly, falsely diagnosed IC patients in this study were not identified. 
While the specificity of Rose Questionnaire and an ABI criteria appears to have a good sensitivity for diagnosing IC, this combination may still fail to diagnose some patients with IC. There are a few indications that this may have occurred for women in the present study. Men but not women in the subgroup IC had deteriorated WIQ scores over time. This can be explained if men had correctly diagnosed IC in 2004 that then deteriorated over time at a pace that can be expected for IC patients, while some women had a walking problems caused by a non-vascular disease that doesn't deteriorate at the same rate. One example of such could be spinal stenosis [27]. It is also reported that women with IC ambulate slower than men, which can influence diagnosis [28]. In our study, on the other hand, there was an identical reduction in $\mathrm{ABI}$ and walking distances over time in both sexes with IC. Another possibility is that WIQ is not an accurate instrument for assessing walking ability in women. WIQ is validated against treadmill walking but atypical leg symptoms are not well covered by this instrument [29].

Interestingly, women from the Group 2 (control) scored lower in all WIQ domains, and thus experienced more leg problems, despite men reporting more concomitant CV disease. In general, women's walking problems appear to be more imprecise and distorted by bodily pain, stiffness in joints, discomfort in the chest and general weakness. It is likely that such general perception will make IC symptoms more indistinct in women, and this may influence prevalence data using Rose Questionnaire. Whether more recently developed instruments such as the Edinburgh Claudication Questionnaire or similar ones will solve this potential problem of under-diagnosing IC in women is unknown $[11,30]$. Few studies have addressed the problem of atypical IC symptoms in PAD but it is well-documented for coronary heart disease [31-33].

Diagnosis of IC also depends on the degree of walking impairment but all subjects with IC needs to be diagnosed to enable $\mathrm{CV}$ risk reduction measures, including very mild IC, that do not requires symptomatic treatment. Whether women and men with IC have different walking abilities is unknown. Gardner et al. reported that men and women with IC had similar 6MWT walking distances, but in a treadmill test women walked shorter distances [34]. The explanation given for this observation was a reduced pulmonary function that influenced walking ability in women. McDermott also found a greater functional impairment among women with IC compared to men. The reason given was diminished leg muscle strength in women [27]. Our data reports a similar disease distribution between the sexes on DUS and a possibly better heart function in women, opposing the notion that women have less severe PAD. Overall it is difficult to find clear support for an appropriate sex difference in resource allocation for symptomatic treatment of IC.

The severity of walking impairment is only one component of the clinical entity IC that is important to consider when deciding whether a patient should be offered symptomatic treatment. A short walking distance might be a severe disability for one person but perfectly acceptable for another. While the only sex-differences in ICQ scores concerned leg pain (where men experienced more problems), women reported lower physical function and ability to perform daily life activities. These results are consistent with a previous data where women perceived a lower physical function, mood state and greater bodily pain than men despite similar disease severity $[31,35]$. Accordingly, there appears to be a clear sex difference in perception of the limitation caused by IC. This difference may be a consequence of divergent walking habits and needs. In the interviews performed in this study it was obvious that men were more physically active than women and that women did not leave their houses as often and were more dependent of support $[24,35,36]$. Despite the fact that a compromised walking ability is the main feature of IC disease, only $34 \%$ of the subjects in Group 3, who reported that they could walk slightly more than $100 \mathrm{~m}$, had been subject to medical care for their disease, and more men had received treatment. If women tend to ignore the severity of their IC symptoms they do not look for medical care.

Some limitations of this study are apparent. Few statistically significant differences between the sexes were observed in Part B, which could be caused by the small cohort size and it is possible that larger and more significant differences between the sexes would have been identified if a larger cohort had been recruited. Another potential issue is the ability to generalize our results to the entire IC population. Group 3 was an acceptable approximation of the demographics of Group 2 (Table 4 ), but while criteria used to identify this cohort are applicable for epidemiology studies but not entirely consistent with day to day clinical praxis as for example self reported questionnaires.

\section{Conclusion}

Sex differences in the description of IC symptoms may influence diagnosis even if objective features of PAD are similar. Men claim to suffer from more pain while women have a greater walking impairment and describe symptoms more atypical. IC prevalence and its consequences may be underestimated in women and this need to be considered in epidemiological studies, clinical trials and as indication for revascularization. 
Table 4 Baseline characteristics for Group 2 and 3

\begin{tabular}{lcccc}
\hline & $\begin{array}{c}\text { Group 2 } \\
\mathbf{N}=\mathbf{3 3 3}\end{array}$ & $\begin{array}{c}\text { Group 2 } \\
\text { Except group 3 } \\
\mathbf{N}=\mathbf{2 4 5}\end{array}$ & $\begin{array}{c}\text { Group 3 } \\
\mathbf{N}=\mathbf{8 8}\end{array}$ & p-values \\
\hline Age & $76.7(7.9)$ & $76.2(7.0)$ & $78.0(7.9)$ & 0.97 \\
ABI & $0.69(0.16)$ & $0.70(0.17)$ & $0.68(0.15)$ & 0.14 \\
Diabetes & $74(22.2 \%)$ & $61(24.9 \%)$ & $13(14.8 \%)$ & 0.05 \\
Hypertension & $183(54.9)$ & $133(54.3)$ & $50(56.8 \%)$ & 0.71 \\
Stroke & $50(15.0 \%)$ & $38(15.5 \%)$ & $12(13.6 \%)$ & 0.73 \\
CAD & $34(10.2 \%)$ & $25(10.2 \%)$ & $9(10.2 \%)$ & 1.00 \\
Smoking & $208(62.5 \%)$ & $153(62.5 \%)$ & $55(62.5 \%)$ & 1.00 \\
\hline
\end{tabular}

Differences betwen group are tested by Fisher's exact test except for age and $A B I$ where the t-test Mann-Whiney's U-test was used respectively.

Accordingly, the results of this study suggest that atypical symptoms of IC among women should be viewed as having a similar consequence on exercise performance as that of classical IC or similar.

\section{Additional material}

Additional file 1: Methodology and evaluation of Duplex ultrasound and Echocardiography. An appendix with detailed description of methodology of preformed Duplex ultrasound of leg arteries and Echocardiography

\section{Abbreviations}

PAD: Peripheral Arterial Disease; IC: Intermittent Claudication; ABI: Ankle Brachial index; SPPS: Swedish PAD Prevalence Study; CV: Cardio Vascular; WIQ: Walking Impairment Questionnaire; ICQ: Intermittent Claudication Questionnaire; 6MWT: Six minutes Walking Test; QoL: Quality of Life; DUS: Duplex Ultra Sound; EF: Ejection Fraction.

\section{Acknowledgements}

This study was supported by funding from the Swedish Heart and Lung Foundation, and County of Värmlands Medical Research Centre and Linköping University. We thank Susanne Sjöstedt,. Leif Bojö, Nils- Göran Ahlin and for their help with the data collection and Irene Jensen for her great contribution with this study.

\section{Author details}

${ }^{1}$ Karolinska Institutet, Stockholm, Sweden. ${ }^{2}$ Dept. of Surgery, Karlstad Hospital, Sweden. ${ }^{3}$ Medical Research Centre, Karlstad Hospital, Sweden. ${ }^{4}$ Dept. of Physiology, Karlstad Hospital, Sweden. ${ }^{5}$ Dept. of Surgery, Uppsala University Hospital, Sweden. ${ }^{6}$ The Heart Centre, Linköping University Hospital, Sweden.

\section{Authors' contributions}

BS designed and coordinated the study, participated in the data analysis and writing of the paper. FL preformed the statistical analysis. BN collected data and participated in data analyses and commented the draft. DB participated in the design and commented the draft. EW designed, participated in the data analysis and writing of the paper All authors read and approved the final manuscript.

\section{Competing interests}

E Wahlberg has received independent research grants from. Pfizer AB. and speakers fees from Bayer-Schering, and BMS .F Lundin, B Nisslon D Bergqvist and B Sigvant declare that they have no financial competing interests

Received: 8 February 2011 Accepted: 30 June 2011

Published: 30 June 2011

\section{References}

1. Sigvant B, Wiberg-Hedman K, Bergqvist D, Rolandsson O, Andersson B, Persson E, Wahlberg E: A population-based study of peripheral arterial disease prevalence with special focus on critical limb ischemia and sex differences. J Vasc Surg 2007, 45(6):1185-1191.

2. Meru AV, Mittra S, Thyagarajan B, Chugh A: Intermittent claudication: an overview. Atherosclerosis 2006, 187(2):221-237.

3. McDermott MM, Greenland P, Liu K, Guralnik JM, Criqui MH, Dolan NC, Chan C, Celic L, Pearce WH, Schneider JR, et al: Leg symptoms in peripheral arterial disease: associated clinical characteristics and functional impairment. Jama 2001, 286(13):1599-1606.

4. Nehler MR, McDermott MM, Treat-Jacobson D, Chetter I, Regensteiner JG: Functional outcomes and quality of life in peripheral arterial disease: current status. Vascular medicine (London, England) 2003, 8(2):115-126.

5. Mostaza JM, Martin-Jadraque R, Vicente I, San Martin MA, Lahoz C: Patients at high risk of cerebrovascular disease: the REACH study. Cerebrovascular diseases (Basel, Switzerland) 2009, 27(Suppl 1):77-81.

6. Vouyouka $A G$, Kent $\mathrm{KC}$ : Arterial vascular disease in women. J Vasc Surg 2007, 46(6):1295-1302.

7. Sigvant B, Wiberg-Hedman K, Bergqvist D, Rolandsson O, Wahlberg E: Risk factor profiles and use of cardiovascular drug prevention in women and men with peripheral arterial disease. Eur J Cardiovasc Prev Rehabil 2009, 16(1):39-46.

8. The Swedish National Registry for Vascular Surgery. 2010.

9. Arslanian-Engoren C, Patel A, Fang J, Armstrong D, Kline-Rogers E, Duvernoy CS, Eagle KA: Symptoms of men and women presenting with acute coronary syndromes. The American journal of cardiology 2006, 98(9):1177-1181.

10. Kosuge M, Kimura K, Ishikawa T, Ebina T, Hibi K, Tsukahara K, Kanna M, Iwahashi N, Okuda J, Nozawa N, et al: Differences between men and women in terms of clinical features of ST-segment elevation acute myocardial infarction. Circ J 2006, 70(3):222-226.

11. Leng GC, Fowkes FG: The Edinburgh Claudication Questionnaire: an improved version of the WHO/Rose Questionnaire for use in epidemiological surveys. Journal of clinical epidemiology 1992, 45(10):1101-1109.

12. Regensteiner JG, Gardner A, Hiatt WR: Exercise testing and exercise rehabilitation for patients with peripheral arterial disease: status in 1997. Vascular medicine (London, England) 1997, 2(2):147-155.

13. Schroder F, Diehm N, Kareem S, Ames M, Pira A, Zwettler U, Lawall H, Diehm C: A modified calculation of ankle-brachial pressure index is far more sensitive in the detection of peripheral arterial disease. J Vasc Surg 2006, 44(3):531-536.

14. Montgomery PS, Gardner AW: The clinical utility of a six-minute walk test in peripheral arterial occlusive disease patients. Journal of the American Geriatrics Society 1998, 46(6):706-711.

15. Chong PF, Garratt AM, Golledge J, Greenhalgh RM, Davies AH: The intermittent claudication questionnaire: a patient-assessed conditionspecific health outcome measure. J Vasc Surg 2002, 36(4):764-771, discussion 863-764.

16. Lang RM, Bierig M, Devereux RB, Flachskampf FA, Foster E, Pellikka PA, Picard MH, Roman MJ, Seward J, Shanewise JS, et al: Recommendations for chamber quantification: a report from the American Society of Echocardiography's Guidelines and Standards y. J Am Soc Echocardiogr 2005, 18(12):1440-1463.

17. Heald CL, Fowkes FG, Murray GD, Price JF: Risk of mortality and cardiovascular disease associated with the ankle-brachial index: Systematic review. Atherosclerosis 2006, 189(1):61-69.

18. Zheng ZJ, Sharrett AR, Chambless LE, Rosamond WD, Nieto FJ, Sheps DS, Dobs A, Evans GW, Heiss G: Associations of ankle-brachial index with clinical coronary heart disease, stroke and preclinical carotid and popliteal atherosclerosis: the Atherosclerosis Risk in Communities (ARIC) Study. Atherosclerosis 1997, 131(1):115-125.

19. Meijer WT, Hoes AW, Rutgers D, Bots ML, Hofman A, Grobbee DE: Peripheral arterial disease in the elderly: The Rotterdam Study. Arterioscler Thromb Vasc Biol 1998, 18(2):185-192.

20. Kannel WB, McGee DL: Update on some epidemiologic features of intermittent claudication: the Framingham Study. Journal of the American Geriatrics Society 1985, 33(1):13-18.

21. Hooi JD, Stoffers HE, Kester AD, Rinkens PE, Kaiser V, van Ree JW, Knottnerus JA: Risk factors and cardiovascular diseases associated with 
asymptomatic peripheral arterial occlusive disease. The Limburg PAOD Study. Peripheral Arterial Occlusive Disease. Scand J Prim Health Care 1998, 16(3):177-182.

22. Bothig S, Metelitsa VI, Barth W, Aleksandrov AA, Schneider I, Ostrovskaya TP, Kokurina EV, lliushina IP, Gurevich LS: Prevalence of ischaemic heart disease, arterial hypertension and intermittent claudication, and distribution of risk factors among middle-aged men in Moscow and Berlin. Cor Vasa 1976, 18(2):104-118.

23. Diehm C, Schuster A, Allenberg JR, Darius H, Haberl R, Lange S, Pittrow D, von Stritzky B, Tepohl G, Trampisch HJ: High prevalence of peripheral arterial disease and co-morbidity in 6880 primary care patients: crosssectional study. Atherosclerosis 2004, 172(1):95-105.

24. Higgins JP, Higgins JA: Epidemiology of peripheral arterial disease in women. J Epidemiol 2003, 13(1):1-14.

25. EuroQol-a new facility for the measurement of health-related quality of life. The EuroQol Group. Health policy (Amsterdam, Netherlands) 1990, 16(3):199-208.

26. Bendermacher BL, Teijink JA, Willigendael EM, Bartelink ML, Buller HR, Peters RJ, Boiten J, Langenberg M, Prins MH: Symptomatic peripheral arterial disease: the value of a validated questionnaire and a clinical decision rule. Br J Gen Pract 2006, 56(533):932-937.

27. MCDermott MM, Greenland P, Liu K, Criqui MH, Guralnik JM, Celic L, Chan C: Sex differences in peripheral arterial disease: leg symptoms and physical functioning. Journal of the American Geriatrics Society 2003, 51(2):222-228.

28. Gardner AW, Parker DE, Montgomery PS, Khurana A, Ritti-Dias RM, Blevins SM: Gender differences in daily ambulatory activity patterns in patients with intermittent claudication. J Vasc Surg 2010, 52(5):1204-1210.

29. Mehta T, Venkata Subramaniam A, Chetter I, McCollum P: Disease-specific quality of life assessment in intermittent claudication: review. Eur J Vasc Endovasc Surg 2003, 25(3):202-208.

30. Bendermacher BL, Willigendael EM, Teijink JA, Prins MH: Medical management of peripheral arterial disease. J Thromb Haemost 2005, 3(8):1628-1637.

31. Stramba-Badiale M, Fox KM, Priori SG, Collins P, Daly C, Graham I, Jonsson B, Schenck-Gustafsson K, Tendera M: Cardiovascular diseases in women: a statement from the policy conference of the European Society of Cardiology. European heart journal 2006, 27(8):994-1005.

32. Granot M, Goldstein-Ferber S, Azzam ZS: Gender differences in the perception of chest pain. Journal of pain and symptom management 2004, 27(2):149-155.

33. DeVon HA, Zerwic JJ: Symptoms of acute coronary syndromes: are there gender differences? A review of the literature. Heart Lung 2002, 31(4):235-245.

34. Gardner AW: Sex differences in claudication pain in subjects with peripheral arterial disease. Med Sci Sports Exerc 2002, 34(11):1695-1698.

35. Vogt MT, Cauley JA, Kuller LH, Nevitt MC: Functional status and mobility among elderly women with lower extremity arterial disease: the Study of Osteoporotic Fractures. Journal of the American Geriatrics Society 1994, 42(9):923-929.

36. Cheanvechai V, Harthun NL, Graham LM, Freischlag JA, Gahtan V: Incidence of peripheral vascular disease in women: is it different from that in men? The Journal of thoracic and cardiovascular surgery 2004, 127(2):314-317.

Pre-publication history

The pre-publication history for this paper can be accessed here: http://www.biomedcentral.com/1471-2261/11/39/prepub

doi:10.1186/1471-2261-11-39

Cite this article as: Sigvant et al:: Differences in presentation of symptoms between women and men with intermittent claudication.

BMC Cardiovascular Disorders 2011 11:39.

\section{Submit your next manuscript to BioMed Central and take full advantage of:}

- Convenient online submission

- Thorough peer review

- No space constraints or color figure charges

- Immediate publication on acceptance

- Inclusion in PubMed, CAS, Scopus and Google Scholar

- Research which is freely available for redistribution

Submit your manuscript at www.biomedcentral.com/submit
Biomed Central 